\title{
Papel do Preceptor da Atenção Primária em Saúde na Formação da Graduação e Pós- Graduação da Universidade Federal de Pernambuco - um Termo de Referência
}

\section{The Primary Health Care Preceptor in Undergraduate and Graduate Training at Pernambuco Federal University: a Reference Term}

Vitor Hugo Lima Barreto Regina Onezifora da Silva Monteiro Gustavo Sérgio de Godoy Magalhães ${ }^{I I}$ Rodrigo Cariri Chalegre de Almeida ${ }^{I}$ Lara Neves Souza

\section{PALAVRAS-CHAVE \\ - Preceptoria. \\ - Atenção Primária à Saúde. \\ - Educação na Saúde.}

Recebido em: 16/11/2010

Reencaminhado em: 10/07/2011

Aprovado em: 08/09/2011

O objetivo principal deste artigo é apresentar uma orientação teórica e prática aos preceptores da atenção primária à saúde vinculados à Universidade Federal de Pernambuco. Pressupõe a atenção primária à saúde como um cenário de prática para estudantes de diferentes graduações e pós-graduações com características próprias. Aborda aspectos importantes do processo ensino-aprendizagem no ambiente comunitário, articulando os diferentes atores deste, entre os quais o conceito de conhecimento na atenção primária; a relação preceptor-estudante; a correlação teoria e prática; a avaliação processual; o ensino e a pesquisa no trabalho; a inserção político-social da aprendizagem; a interdisciplinaridade; o trabalho em equipe e a interinstitucionalidade na integração ensino-serviço. Por fim, propõe a reintegração do espaço da educação, da pesquisa e do trabalho.

This article aims to present a theoretical and practical guideline to primary health care preceptors connected to the Pernambuco Federal University. Primary health care is presumed as a practical setting for students of different undergraduate and graduate courses, with their own characteristics. Important aspects of the teaching-learning process in the community are addressed, including the concept of knowledge in primary care; the preceptor-student relationship; theory-practice correlation; procedural assessment; education and research at work; socio-political context of learning; interdisciplinarity; teamwork and cross-institutional service-learning integration. Finally, it proposes the reintegration of the learning, research and work space.

Prefeitura da Cidade do Recife, Recife, PE, Brasil 


\section{INTRODUÇÃO}

No contexto do Sistema Único de Saúde, Campos $^{1}$ afirma que as funções da atenção primária à saúde (APS) podem ser resumidas em três princípios: o primeiro ressalta a importância do acolhimento à demanda da população e a busca ativa por meio da avaliação de vulnerabilidades; o segundo enfatiza a Clínica Ampliada como ferramenta para a gestão do cuidado de usuários, profissionais e gestores ${ }^{3}$; o terceiro concerne à promoção e prevenção, princípios enfatizados pelos conhecimentos do campo da Saúde Coletiva.

Para possibilitar a concretização dessas funções, a APS está estruturada por meio de uma política nacional, cujas diretrizes apoiam os três princípios descritos acima. As diretrizes fortalecem o trabalho em equipe interdisciplinar e a corresponsabilidade sanitária por um território, tanto da equipe quanto da gestão; enfatizam a produção de vínculos entre a equipe e os usuários; ressaltam a abordagem do sujeito, da família e do contexto em busca da integralidade. Propõem ainda uma reformulação do saber e da prática tradicional em saúde e a articulação da APS com uma rede de serviços de saúde.

Em conjunto com a reformulação do sistema de saúde, apresenta-se em igual processo de transição a educação dos profissionais de saúde na graduação e pós-graduação. Nesta perspectiva, Cunha ${ }^{4}$ apresenta uma classificação de dois modelos de ensino: um tradicional e um emergente. No tradicional, o ensino é centrado no professor ou preceptor, com ênfase na transmissão do conhecimento, enquanto no ensino emergente a coprodução de autonomia é o foco de todas as relações existentes na produção do cuidar. Neste contexto, o preceptor de serviço tem papel fundamental na apropriação, por parte dos estudantes, de competências para a vida profissional, incluindo conhecimentos, habilidades e atitudes.

Pretende-se neste artigo apresentar diretrizes para o papel do preceptor da atenção primária em saúde (APS) no ensino da graduação e pós-graduação na Universidade Federal de Pernambuco.

\section{METODOLOGIA}

A necessidade do termo surgiu a partir das discussões de situações-problema (casos clínicos e outras situações da assistência) do programa de residência em Medicina de Família e Comunidade de que participavam residentes, preceptores, internos e professores de Medicina Social e Clínica Médica. Diante da constatação da existência de concepções diferentes para a atuação da preceptoria, gerou-se um documento de base no formato diferenciado proposto pelo programa de residência e seus participantes. A partir de então, o autor se responsabilizou por produzir um texto inicial, que seria discutido através das listas de comunicação à distância do programa de residência, do núcleo pedagógico do curso médico da UFPE (Nuped) e da Associação Pernambucana de Medicina de Família e Comunidade (APEMFC). Decorrido um mês, os comentários, sugestões e críticas foram acolhidos, e modificações no texto foram realizadas. Atualmente, o documento faz parte das referências utilizadas para o Manual de Preceptoria do curso de Medicina da UFPE, que está em processo de elaboração.

\section{DIRETRIZES PARA A PRECEPTORIA NA ATENÇÃO PRIMÁRIA À SAÚDE}

Na relação educativa da APS, destacam-se oito aspectos fundamentais à construção de um processo de formação compatível com um ensino emergente ou ensino de um conhecimento prudente para uma vida decente, como descrito por Santos ${ }^{5}$, ao questionar o conhecimento na perspectiva do ensino tradicional. Cada um desses aspectos será detalhado com o intuito de proporcionar uma reflexão conceitual sobre suas bases teóricas, além de demonstrar, paralelamente, suas diferenças em relação à preceptoria em um modelo tradicional, mais comum em outros níveis da atenção à saúde. Os aspectos apresentados constituirão as diretrizes a serem utilizadas por professores, preceptores, gestores e estudantes para pensar o processo ensino-aprendizagem na sua prática diária. São eles:

1. Concepção de conhecimento;

2. Relação preceptor-educando;

3. Relação teoria-prática;

4. Relação ensino-pesquisa-trabalho;

5. Avaliação;

6. Inserção político-social da aprendizagem;

7. Construção da interdisciplinaridade;

8. Pactuação interinstitucional.

\section{O Conhecimento na APS}

O conhecimento desenvolvido na APS tem como característica básica estar sempre em construção e em questionamento, sem a perspectiva de verdades absolutas ${ }^{6}$. A dúvida sobre a prática é sempre o ponto de partida para a aprendizagem, e sua resolução consiste em processo criativo, produzido pela relação educando-usuário-preceptor, considerando a coprodução da saúde e sua compreensão ${ }^{7}$ e desconstruindo a disjunção objeto-sujeito ${ }^{8}$.

Sem a possibilidade do isolamento hospitalar, o conhecimento biomédico é atravessado por outros conhecimentos, principalmente da psicologia humana, das ciências sociais e do saber popular, trazendo ao primeiro uma significância diferenciada no momento em que reintegra os conhecimentos ${ }^{8}$. Possibilita-se, desta forma, a reconstrução do conhecimento 
científico em senso comum, no momento em que este se transformará em ações de saúde no cotidiano da comunidade 5 .

O erro será visto como procedimento integrante da aprendizagem, sendo, portanto, valorizado enquanto etapa a ser percorrida, com as devidas responsabilizações.

Incorpora-se, ainda nesta perspectiva, a incrível revolução que acontece na própria produção e democratização do conhecimento através das tecnologias da informação. O espaço virtual suporta tecnologias intelectuais que ampliam, exteriorizam e alteram muitas funções cognitivas humanas: a memória (bancos de dados, hipertextos, fichários digitais de todas as ordens), a imaginação (simulações), a percepção (sensores digitais, telepresença, realidades virtuais), os raciocínios (inteligência artificial, modelização de fenômenos complexos). É fortalecida a noção de conhecimento em constante coprodução, uma verdadeira inteligência coletiva ${ }^{9}$, conceituada por Pierre Levy.

É essa perspectiva de conhecimento que norteará as próximas diretrizes referentes ao ensino na APS.

\section{A relação preceptor-educando}

A relação entre preceptor e educando é um importante instrumento para a descoberta do trabalho coletivo. Para que isto aconteça, é importante aceitar e valorizar o que o educando traz enquanto conhecimento teórico e sentimentos ${ }^{10}$. Estimula-se nesta relação o ato de pensar, construindo hipóteses e as ratificando ou retificando.

O preceptor desenvolve o ato da crítica amorosa e cuidadora, sem a perspectiva de inferiorizar o estudante. A relação se horizontaliza quando o preceptor não é nem pretende ser a voz da verdade. Foge-se, portanto, da educação bancária, na qual o estudante é depositário do saber do preceptor ${ }^{11}$. Distancia-se também da relação de dependência mãe-bebê, em que o estudante apenas abre a boca para receber o leite (conhecimento) do seio materno (preceptor). Ressalta-se nesta metáfora a manutenção de uma relação de dependência e de superioridade entre preceptor e educando.

Na prática da educação médica, é fácil perceber o tipo de relacionamento em que a hierarquização da relação preceptor-residente-graduando-usuário se dá abertamente. Neste sistema, cabe ao residente e ao graduando todo o trabalho considerado físico e repetitivo, e ao preceptor o trabalho intelectual e de reflexão. Paralelamente a este processo, ocorre a precarização do serviço público, exercido pelos educandos, enquanto o preceptor privilegia os espaços do serviço privado em sua carga horária. O educando se constrói, assim, através da superação das barreiras de inferiorização que sofre durante todo o processo de aprendizagem (no qual aprende inclusive a reproduzir o mesmo modelo aos que se seguem). Desta forma, concretiza-se um currículo oculto, que consiste na aquisição de conhecimentos, habilidades e principalmente atitudes não dispostos nos projetos pedagógicos, mas observados no dia a dia da prática do preceptor ${ }^{12}$.

Cabe, portanto, ao preceptor e ao educando na APS a não reprodução deste modelo, tendo em vista as dificuldades inerentes a um processo educativo não vivenciado em outros espaços de suas formações profissionais, reforçando o caráter coprodutivo e inovador deste processo. Para tanto, será importante incorporar algumas práticas a fim de horizontalizar a relação, como, por exemplo:

1. Atitudes a serem tomadas pelo preceptor para facilitar a aprendizagem intelectual e afetiva:

a. Veracidade e autenticidade: ser o que se é, sem construção de fachadas;

b. Prezar, aceitar e confiar: respeitar o estudante e o que ele traz de conhecimento;

c. Compreensão empática: compreender o estudante enquanto ser humano, evitando julgamentos ${ }^{10}$;

2. Abertura concreta entre todos para sanar dúvidas e inseguranças, inclusive do preceptor;

3. Organização do processo de trabalho que comporte o ensino;

4. Responsabilização equânime do processo de trabalho;

5. Compromisso efetivo do preceptor e educando com sua responsabilidade territorial, epidemiológica e educacional;

6. Incorporação, no relacionamento com os usuários, de características semelhantes às do relacionamento com o educando, dado que o usuário está também em processo educativo sobre sua produção de saúde.

\section{Apropriação e Produção do Conhecimento Teórico a partir da Prática}

Tendo a dúvida como pilar essencial, são os problemas reais da comunidade que produzirão a necessidade do saber teórico. O fluxo do conhecimento adquire o seguinte caminho: dúvida advinda da prática; teorização da prática; experimentação da teoria na prática; reteorização a partir da experiência aplicada, e assim sucessivamente.

Os conhecimentos adquiridos e produzidos, portanto, serão sempre contextualizados para cada situação específica, sendo, portanto, provisórios, assumindo um cotidiano de ação e reflexão ${ }^{4}$. Para isto, convém utilizar as seguintes estratégias para desenvolver a capacidade de reflexão ${ }^{13}$ : análise de casos; narrativas orais; confronto de opiniões e abordagens; grupos de discussão ou círculos de estudo; auto-observação; perguntas pedagógicas. 
Na integração do saber teórico à prática, o preceptor não espera que o educando memorize referenciais laboratoriais, fórmulas matemáticas, nem critérios diagnósticos, mas que desenvolva a capacidade de acessar as informações certas para cada situação-problema. O educando deverá aprender a acessar as informações das mais variadas fontes, como biblioteca da própria USF, banco de dados em computador de mão, bibliotecas virtuais e base de dados como o UpToDate, entre outras. As informações virão também através de outros profissionais da rede de referência, além de movimentos sociais de usuários, amigos de turma, etc., construindo, assim, uma rede de conhecimento que lhe possibilite maior resolutividade.

Espera-se que o estudante possa desenvolver uma cartografia do conhecimento ${ }^{14}$, que será constantemente alimentada pela resolução dos problemas, principalmente através da estratégia do currículo baseado no cuidado ${ }^{15}$. Este mapa mental dos vários caminhos para determinados conhecimentos será acessado constantemente pelo educando e pelo preceptor na resolução das vivências. Diante da quase ilimitada capacidade de armazenamento de dados disponível na atualidade, o educando, bem como o preceptor, tem a oportunidade de desenvolver outras funções cognitivas, afetivas e psicomotoras que não a simples memorização. Eles poderão se dedicar a conhecer aspectos da psicologia humana, das ciências sociais e do saber popular, a fim de produzir vínculo com o usuário, as famílias e a comunidade. Taxonomias como as de Bloom, de Lapatra e Problematização, com suas especificidades e diferenças, são instrumentos importantes para o acompanhamento sistemático do educando.

\section{Inserção do ensino e pesquisa no ambiente de trabalho}

Uma característica fundamental do ensino na APS é a possibilidade concreta de integração com o ambiente de trabalho. Referimo-nos a uma integração concreta, dada a lógica de desintegração existente entre os mundos do trabalho e do ensino. Esta lógica perversa produz no trabalho um ambiente morto, sem criatividade e que apenas reproduz modelos técnicos distantes, teorizados por autores endeusados ${ }^{16}$. O ambiente exclusivamente de ensino, porém, também constitui um modelo limitado, dada a centralidade no desejo de seus atores. A complexa realidade e suas necessidades são filtradas pelos desejos da instituição e seus protagonistas.

É bastante comum o relato de estudantes que encontram nas unidades de saúde da família um trabalhador de saúde desmotivado, desatualizado, adoecido e precarizado. Também é comum observar nas enfermarias de hospitais-escolas leitos ocupados principalmente através do desejo dos educandos e preceptores em patologias específicas, sem qualquer gestão da demanda de internamento hospitalar da realidade onde se inserem. $\mathrm{O}$ trabalho nessas instituições também se precariza no momento em que o preceptor deixa sob a responsabilidade do educando o serviço de saúde-ensino (geralmente público), priorizando os serviços de saúde privados.

O preceptor da APS tem por compromisso a articulação do Trabalho Morto com o Trabalho Vivo e nesta articulação possibilitar o ambiente de ensino e a produção de conhecimento ${ }^{16}$.

Para isto, é necessário ao preceptor:

1. Manutenção de suas responsabilidades territoriais e epidemiológicas em conjunto com o ensino e a pesquisa;

2. Inserção adequada do educando nas responsabilidades do serviço, dando-lhe um caráter "participa-ativo", "colabora-ativo", por meio de uma agenda de atividades compatíveis com seus objetivos de aprendizagem. Exemplo:

a. Estudantes do segundo ano: ações em promoção e prevenção;

b. Estudantes do quinto e sexto anos: ações em promoção, prevenção, cura e reabilitação;

c. Estudantes de pós-graduação: ações em promoção, prevenção, cura, reabilitação, gestão, etc.;

3. Adequação dos atendimentos ao contexto do ensino, lembrando que o número de atendimentos, visitas, atividades educativas, etc. não será modificado para mais, explorando o trabalho do educando, nem para menos, minimizando as necessidades da população.

\section{Avaliação processual e por competências}

Consideramos que não existe o hábito da avaliação na grande maioria dos programas de ensino em serviço, na graduação ou na pós-graduação. Mesmo assim, quando existe, reproduz os métodos de avaliação tradicionais, centrados em provas objetivas, pontuais, no final do módulo, ou rodízio, com caráter apenas quantitativo, para dar uma nota e estimular os estudantes a estudar fora do contexto da realidade. Estes métodos já foram bastante criticados pela literatura da educação médica ${ }^{16}$.

Levando em conta o projeto pedagógico dos programas de residência médica em Medicina de Família e Comunidade, atualmente centrado no desenvolvimento de conhecimentos, habilidades e atitudes, será importante que as avaliações com os educandos possibilitem o reconhecimento crítico do seu próprio aprendizado por competências. Sendo assim, as avaliações deverão ser subjetivas e objetivas, processuais durante o módulo ou rodízio, com enfoque nas competências a serem desenvolvidas, respeitando os limites, potencialidades e desejos do educando. 
Dessa forma, as avaliações deverão seguir os seguintes princípios:

1. Avaliação centrada na metodologia de grupos focais, com um instrumento fomentador de reflexão a ser preenchido por toda a equipe previamente ao grupo focal;

2. Avaliação objetiva por meio de relatórios, apresentações finais e/ou diário de campo;

3. Acontecimento processual, permitindo sempre a correção de percurso:

a. Mensal para estudantes do quinto e sexto anos;

b. Trimestral para estudantes de pós-graduação.

\section{Inserção Político-social da Aprendizagem}

É na própria história da educação que se encontra a separação entre a vida real e o ensino. Na educação médica, os hospitais universitários são a representação fundamental desta separação: isolam os educandos de seu contexto, construindo uma barreira na percepção concreta das necessidades da maioria da população e nas formas corretas de solucionar as necessidades. Cria-se desta forma uma suposta ciência médica sem um sentido concreto.

Fica uma pergunta no ar: como o grande avanço médico-científico tem contribuído para resolver as principais dificuldades de saúde da população mundial? Para responder esta pergunta, é importante não cometer o mesmo erro de isolar a medicina de seu contexto, levando em consideração as importantes estruturas de poder que influenciam a produção do conhecimento. Valoriza-se, portanto, para a construção de uma ciência pós-moderna, o paradigma do Conhecimento Prudente para uma Vida Decente ${ }^{5}$.

É a partir deste paradigma que a APS se torna um cenário de prática privilegiado para o ensino, por estar intimamente inserida no contexto político-social. Nas comunidades, percebe-se a historicidade de cada aspecto da vida humana, desde o simples ato de se alimentar até as práticas cotidianas de saúde. As resoluções encontradas consideram a mais ampla gama de fatores presentes no complexo contexto comunitário. É importante que o preceptor ressalte estas questões inerentes a todos os atos de saúde, desde as atividades de educação popular à prescrição dos medicamentos, tornando-as alvo de estudo pelos educandos. É importante desenvolver pesquisas científicas que contemplem esta inserção.

\section{Interdisciplinaridade e trabalho em equipe}

A interdisciplinaridade é um dos princípios da APS, porém existem outras estruturas macropolíticas de poder que constroem obstáculos para sua efetivação. Quando a realidade é o ponto de partida e alvo da atenção à saúde, ela já é interdisciplinar por si mesma, delineando, assim, as práticas de saúde. Na unidade de saúde, é importante a pactuação da equipe preceptora, construindo as programações de ensino em conjunto. Desta forma, integra-se o educando a todas as pessoas da equipe de saúde da família, que passam a se sentir responsáveis pela aprendizagem dos estudantes. Para isto, é importante que a equipe se aproprie de técnicas de planejamento educacional.

\section{Pactuação Interinstitucional para Integração Ensino-serviço}

As instituições de ensino e secretarias municipais e estaduais de saúde deverão, a exemplo da Câmara Interministerial de Educação em Saúde, constituir em seus organogramas um espaço democrático para a pactuação da integração ensino-serviço. Entre outras responsabilidades estão:

1. Ênfase maior na importância de um espaço adequado (incluindo estrutura física, população adstrita, recursos de aprendizagem, etc.);

2. Descrição da formação desejável (ou perfil) para um profissional se tornar preceptor, incluindo políticas de educação continuada e integração com a coordenação pedagógica;

3. Construção das ementas dos estágios envolvendo coordenação pedagógica e gestão dos serviços e preceptores.

\section{CONCLUSÃO}

As diretrizes aqui descritas devem servir como base para reflexão das equipes preceptoras da atenção primária, a fim de desenvolver um ensino em serviço compatível com as necessidades de saúde apresentadas pela população na APS. Uma educação emergente só será possível quando a equipe assumir como parte do seu processo de trabalho o ensino na saúde por meio de uma compreensão de educação permanente de si mesma e dos educandos que atravessarem sua história.

\section{REFERÊNCIAS}

1. Associação Brasileira de Educação Médica [homepage]. Rio de Janeiro:ABEM; c2008 [acesso em ]. Posicionamento da ABEM. Campos GWS. Papel da Rede de Atenção Básica em Saúde na Formação Médica - abril de 2005. http:// www.abem-educmed.org.br/posicionamento_abem/ doc_prof_gastao.pdf

2. Brasil. Ministério da Saúde. Acolhimento nas práticas de produção de saúde. 2 ed. Brasilia: MS; 2006. (Série B. Textos Básicos de Saúde Brasília).

3. Cunha GT. A construção da Clínica Ampliada na atenção Básica. São Paulo: Hucitec; 2005. 
4. Cunha MI. O professor universitário na transição de paradigmas. Araraquara:J.M. Editora; 1998.

5. Santos BS. Um discurso sobre as ciências. Porto: Afrontamento; 1987.

6. Rorty R Contingência, ironia e solidariedade. Lisboa: Presença; 1992.

7. Campos GWS. Saúde Paidéia. São Paulo: Hucitec; 2003.

8. Morin E, Carvalho EA, Almeida MC. Educação e complexidade os sete saberes e outros ensaios. São Paulo: Cortez; 2002.

9. Lévy P. Educação e cybercultura. [S.1:Sn];1998 .

10. Rogers CR, Rosenberg RL. A Pessoa com Centro. São Paulo: EdUSP; 1997.

11. Freire P. Pedagogia da autonomia: saberes necessários à prática educativa. São Paulo: Paz e Terra; 1996.

12. Martins MN. O currículo oculto na prática pedagógica. Rev Científica Eletrônica Ciênc Sociais Aplicadas da Eduvale. 2055;4.

13. Alarcão I. Professores reflexivos em uma escola reflexiva. São Paulo:Cortez;2003.

14. Machado NJ. A Universidade e a organização do conhecimento: a rede, o tácito, a dádiva. Estud Av. 2001;15(42): 333-52.

15. Júnior IFS. Currículo baseado no cuidado: a experiência da Residência em Medicina de Família e Comunidade da UFPE. Recife; 2008. Graduação [Monografia] - Universidade Federal de Pernambuco.
16. Merhy EE. Sáude: A cartografia do trabalho vivo. 3 ed. São Paulo: Hucitec; 2002.

17. Piccini RX, Facchini LA, Santos RC. Preparando a transformação da educação médica brasileira: projeto CINAEM III fase: relatório 1999-2000 / CINAEM- Comissão Interinstitucional Nacional de Avaliação do Ensino Médico. Pelotas: UFPel, 2000.

\section{CONTRIBUIÇÃO DOS AUTORES}

Todos os autores contribuíram na concepção e desenho do artigo, divulgação durante a consulta aos grupos participantes da elaboração, confecção e revisão crítica do conteúdo intelectual e aprovação da última versão publicada.

\section{CONFLITO DE INTERESSES}

Declarou não haver.

\section{ENDEREÇO PARA CORRESPONDÊNCIA}

Prefeitura da Cidade do Recife, Unidade de Saúde da Família Coqueiral.

Rua Maria Tereza, 157

Coqueiral - Recife

CEP. 52050-180 - PE

E-mail: barretovitor@hotmail.com 